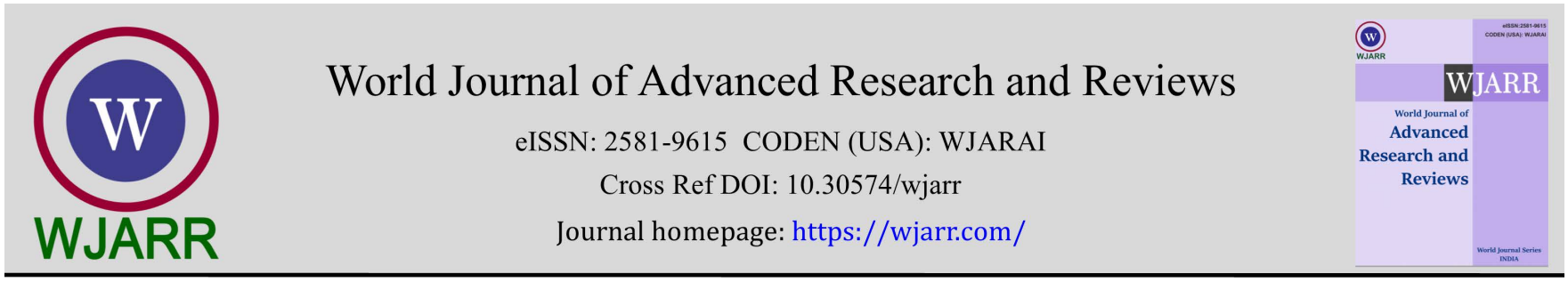

(RESEARCH ARTICLE)

Check for updates

\title{
Swine erysipelas, clinical diagnosis and medical management: cases in farm near the city of Lubumbashi
}

Bonheur kumwimba ${ }^{1,}{ }^{*}$, Hyacinthe nyandwe ${ }^{2}$ and Arthur ngulu nsasi ${ }^{3}$

${ }^{1}$ Assistant, Basic sciences, University of Lubumbashi, Lubumbashi, Haut-Katanga, DRC

${ }^{2}$ Assistant, Clinics, University of Lubumbashi, Lubumbashi, Haut-Katanga, DRC

${ }^{3}$ Professor, Preclinics, University of Lubumbashi, Lubumbashi, Haut-Katanga, DRC

World Journal of Advanced Research and Reviews, 2021, 12(03), 329-333

Publication history: Received on 25 August 2021; revised on 19 October 2021; accepted on 21 October 2021

Article DOI: https://doi.org/10.30574/wjarr.2021.12.3.0491

\begin{abstract}
The general objective of our work was to diagnose swine erysipelas, treat infected pigs and determine the prevalence of this pathology on the farm near the city of Lubumbashi. It is located $30 \mathrm{~km}$ from the city of Lubumbashi, on the axis of the Kasenga road, to the east of the Haut-Katanga Province.
\end{abstract}

This disease plays a key role in perpetuating the downfall of pig farms. That's why we asked ourselves the following questions:

- What would be the categories of pigs most affected by this disease?

- What would be the level of information for breeders and the risk of infection?

- At what rate would the losses be assessed on the farms examined?

This work concerns a farm that experienced swine fever a year earlier and whose pigs were not vaccinated against erysipelas. This disease is a major cause of death in pigs.

The prospective method in clinical diagnosis and care was applied to 98 pigs from 4 zootechnical categories, namely piglets, sows, castrated males and boars. The data collected in this study revealed a prevalence of $81.6 \%$ with a mortality rate of $61.2 \%$ and a cure rate of $20.4 \%$. Only $18.4 \%$ of pigs were not affected by the disease.

The study carried out, involved 98 pigs of different categories including 37 piglets, 35 sows, 6 boars and 20 castrated. These pigs were of exotic Land race, large white, Piétrain and Duroc. There are also hybrid pigs.

We concluded that the results obtained in our research on swine erysipelas concern 98 study animals divided into 4 zootechnical categories. It appeared 80 pigs or $81.6 \%$ were struck by erysipelas and only 18 or $18.4 \%$ had remained healthy. The infection rate was thus $81.6 \%$.

Keywords: Clinics; Therapeutic; Redness; Lubumbashi

\section{Introduction}

Erysipelas is one of the red diseases of pigs. It is caused by a bacterial germ called Erysipelothrix rhusiopathiae [1]

\footnotetext{
* Corresponding author: Kumwimba Mb

Assistant, Basic sciences, University of Lubumbashi, Lubumbashi, Haut-Katanga, DRC.
}

Copyright $(2021$ Author(s) retain the copyright of this article. This article is published under the terms of the Creative Commons Attribution Liscense 4.0. 
In recent years, it has caused sporadic deadly epizootics in herds of turkeys and guinea fowl in France [6].

In sheep, the morbidity rate with arthritis can be quite high, around $20 \%$ in lambs [11].

In pigs, outbreaks have been detected in farms, either without a recent pathological history or at the same time as a major viral disease such as swine fever [8]. Erysipelas has also been found in properly vaccinated animals. This disease plays a key role in perpetuating the downfall of pig farms.

The objective of our work was to diagnose swine erysipelas, treat infected pigs and determine the prevalence of this pathology in a farm near the city of Lubumbashi. A prospective methodology was followed in this work, in particular in clinical diagnosis and in the care given to pigs.

\section{Material and methods}

\subsection{Material}

The study carried out, involved 98 pigs of different categories including 37 piglets, 35 sows, 6 boars and 20 castrated males. These pigs were of exotic breeds: Land race, Large white, Piétrain, Duroc. The farm is located $30 \mathrm{~km}$ from the city of Lubumbashi, located at $12^{\circ} 36^{\prime} 19^{\prime \prime}$ South latitude and $27^{\circ} 28^{\prime} 51$ " East longitude, at $1268 \mathrm{~m}$ altitude. Its climate is tropical, characterized by 7 months of dry season (April to October), followed by 5 months of rainy season (November to March). The annual average temperature is $20^{\circ}$ [9].

\subsubsection{Autopsy and treatment equipment.}

We used gloves, Knife, Scalpel blade, Bucket, Boots and overalls, Anatomical clamps, Hemostatic forceps. For treating pigs, syringes, tourniquet, drugs, thermometer.

\subsection{Methods}

We used clinical examination to make the ante-mortem diagnosis [7]. During autopsy, we applied rigorously collection of history; external examination of the corpse; opening and examination of the abdominal cavity and evisceration; opening of the thoracic cavity and evisceration of the thoracic organs; specific examination of organs and tissues; examination of the musculoskeletal system; incineration of contaminated carcasses.

\section{Results}

For ante-mortem diagnosis, we noticed hyperthermia of $42^{\circ} \mathrm{C}$ in several animals; frequent lameness in adult animals; rhomboic and reddish hypertrophic skin patches on the body of animals with itching sensation; vomiting accompanied by diarrhea; hematuria; dyspnea in several animals; sudden death of animals; blood flow through nostrils of the corpse.

As far as post-mortem diagnosis was concerned, sows, dead from swine erysipelas, showed pigment spots, quadrangular or red rhomboic plaques all over the skin of cadavers. Red spots, ulcers of gastric mucous membranes were observed in sows and red discoloration of corpses in boars.

Noted symptoms like fever, red spots, diarrhea, were observed in all categories of pigs. Arthritis and nervous disorders have been particularly observed in boars and sows.

The affected sows showed a relativel high number with 35 cases, or $35.7 \%$. Boars were the least affected with 6 cases or $6.1 \%$. As for the piglets, they had 24 cases, or $24.5 \%$, a rate higher than that of 15 castrated males, or $15.3 \%$. The prevalence of pigs with erysipelas was $81.6 \%$.

Sows had a higher mortality rate before treatment with $12.2 \%$. Boars had 3 cases or $3.1 \% .2$ cases were were recorded among castrated males, or $2.0 \%$, whereas the piglets had no mortality before treatment.

Piglets remained healthy throughout the study period. However, the mortality rate of $53.1 \%$ was not significant compared to only $24.7 \%$ cured

Boars and sows died. Only $63.0 \%$ of piglets (with $27.0 \%$ ) and $55.0 \%$ of castrated males resisted the disease or were cured. A total of 60 cases perished or $61.2 \%$ mortality. 
Table 1 Erysipelas Prevalence in the farm

\begin{tabular}{|l|l|l|l|l|l|l|}
\hline \multirow{2}{*}{ Zootechnical Category } & \multicolumn{2}{|l|}{ Sick animals } & \multicolumn{2}{l|}{ Safe animals } & \multicolumn{2}{l|}{ Total } \\
\cline { 2 - 7 } & Size & $\mathbf{\%}$ & Size & $\mathbf{\%}$ & Size & \% \\
\hline Weaned piglets & 24 & 24,5 & 13 & 13,3 & 37 & 37,8 \\
\hline Sows & 35 & 35,7 & 0 & 0,0 & 35 & 35,7 \\
\hline Castrated boars & 15 & 15,3 & 5 & 5,1 & 20 & 20,4 \\
\hline Non castrated boars & 6 & 6,1 & 0 & 0,0 & 6 & 6,1 \\
\hline Total & 80 & 81,6 & 18 & 18,4 & 98 & 100,0 \\
\hline
\end{tabular}

Table 2 Mortality and recovery rates during two week treatment

\begin{tabular}{|l|l|l|l|l|l|l|l|l|}
\hline \multirow{2}{*}{ Zootechnical Category } & \multicolumn{2}{l|}{ Dead animals } & \multicolumn{2}{l|}{ Safe animals } & \multicolumn{2}{l|}{ Cured animals } & \multicolumn{2}{l|}{ Total } \\
\cline { 2 - 10 } & Size & $\mathbf{\%}$ & Size & $\mathbf{\%}$ & Size & $\mathbf{\%}$ & Size & \% \\
\hline Weaned piglets & 10 & 12,3 & 14 & 17,3 & 13 & 16,0 & 37 & 45,7 \\
\hline Sows & 23 & 28,4 & 0 & 0,0 & 0 & 0,0 & 23 & 28,4 \\
\hline Castrated boars & 7 & 8,6 & 6 & 7,4 & 5 & 6,2 & 18 & 22,2 \\
\hline Boars & 3 & 3,7 & 0 & 0,0 & 0 & 0,0 & 3 & 3,7 \\
\hline Total & 43 & 53,1 & 20 & 24,7 & 18 & 22,2 & 81 & 100 \\
\hline
\end{tabular}

Table 3 Recorded Global mortality rate

\begin{tabular}{|c|c|c|c|c|c|c|c|c|c|c|}
\hline \multirow{2}{*}{$\begin{array}{l}\text { Zootechnical } \\
\text { Category }\end{array}$} & \multicolumn{2}{|c|}{$\begin{array}{l}\text { 1st Mortality } \\
\text { bunch }\end{array}$} & \multicolumn{2}{|c|}{$\begin{array}{l}\text { 2nd Mortality } \\
\text { bunch }\end{array}$} & \multicolumn{2}{|c|}{$\begin{array}{l}\text { Cured } \\
\text { animals }\end{array}$} & \multicolumn{2}{|c|}{$\begin{array}{l}\text { Safe } \\
\text { animals }\end{array}$} & \multicolumn{2}{|l|}{ Total } \\
\hline & \begin{tabular}{|l|} 
Size \\
\end{tabular} & $\%$ & \begin{tabular}{|l|} 
Size \\
\end{tabular} & $\%$ & Size & $\%$ & Size & $\%$ & Size & $\%$ \\
\hline Weaned piglets & 0 & 0,0 & 10 & 12,2 & 14 & 14,3 & 13 & 13,3 & 37 & 37,8 \\
\hline Sows & 12 & 12,2 & 23 & 23,5 & 0 & 0,0 & 0 & 0,0 & 35 & 35,7 \\
\hline Castrated Boars & 2 & 2,0 & & 7,1 & 6 & 6,1 & 5 & 5,1 & 20 & 20,4 \\
\hline Boars & 3 & 3,1 & 3 & 3,1 & 0 & 0,0 & 0 & 0,0 & 6 & 6,1 \\
\hline Total & 17 & 17,3 & 43 & 43,9 & 20 & 20,4 & 18 & 18,4 & 98 & 100 \\
\hline
\end{tabular}

\section{Discussion}

The results obtained in our research on swine erysipelas were about 98 animals divided into 4 zootechnical categories, namely: breeding sows, weaned piglets, castrated males and boars. It appeared that 80 or $81.6 \%$ were struck by erysipelas and only 18 or $18.4 \%$ had remained healthy. The infection rate was thus $81.6 \%$. This rate was higher than that of $20 \%$ found by MULUMBA-NFUMU [10] in 2015 in Kinshasa, in pigs from Kingantoko.

The situation of the examined farm can be linked to a few factors. Indeed, anyone who arrived at the farm should pass through the pigsty before reaching the administrative offices, the dining hall and the agricultural shed. In addition, the equipment used in the pigsty, the henhouse and the animal park is common; it could be involved in interspecific contaminations thanks to the factors of concurrent diseases.

Swine fever, for example, struck this farm in 2015 , one year before we undertook the current study. Swine fever contributes to reducing the resistance of the organism, thus breaking the state of equilibrium of animals TOMA [13]. This state of affairs allows the maintenance of a latent carriage of the germ and promotes tissue dissemination from 
digestive entry doors (lymphoid formation). Swine fever would be a trigger. From a hygienic point of view, a footbath was available to pigs which did not use it.

Poor cleaning of feeders and waterers, mixed feed on the floor are other contributing factors. The studies of PASTEUR [12] underlined the economic losses related to the erysipelas when he mentioned the death of more than a million pigs in the United States as well as the attributable devastation of the disease in France, and in England. The current study reports a death rate of $61.2 \%$. Considering the before and the course of treatment, the mortality rate was $17.3 \%$ and $43.9 \%$ respectively. Mortality was highest during treatment (Table 2). This result falls within the range taken from the statement by CHAILLON [6] according to which, pig mortality in France varies between 20 and $80 \%$. In addition, it is observed that all 41 breeding pigs of both sexes died or $41.8 \%$ with $35.7 \%$ sows and $6.1 \%$ boars.

The $11.2 \%$ recorded in castrated males brought the total to $62.5 \%$. This is because adult pigs are the most susceptible animals to erysipelas bacilli. It is here that BENET [3] states that piglets are protected by colostrum between 4 and 15 weeks. In this study, $35.1 \%$ of the piglets resisted swine erysipelas while $37.8 \%$ were cured of the disease. Thus a total of 27 piglets or $72.9 \%$ remained alive.

Arthritis was the most common sign in boars along with nervous disorders and fever. In piglets, the situation was somewhat different as the most frequent signs were red patches on the skin, fever and vomiting. In sows, characteristic skin changes were also observed, mainly in the ears, the snout, the neck and the skin of the trunk in the form of rhomboid spots BENEDICTE [2]. Macroscopic lesions of the organs were most often observed: to the liver, spleen, heart, skin, kidney and digestive tract. Due in particular to its cardiac involvement and arthritis, erysipela is considered a notifiable disease.

\section{Conclusion}

This study concerned a farm that experienced swine fever a year earlier and whose pigs were not vaccinated against erysipelas. This disease is a major cause of death in pigs.

The objective of our work was to diagnose swine erysipelas, treat infected pigs and determine the prevalence of this pathology in a farm near the city of Lubumbashi. The prospective method in clinical diagnosis and care was applied to 98 pigs from 4 zootechnical categories, namely piglets, sows, castrated males and boars. The data collected in this study revealed a prevalence of $81.6 \%$ with a mortality rate of $61.2 \%$ and a cure rate of $20.4 \%$. Only $18.4 \%$ of pigs were not affected by the disease.

Faced with this situation, it was necessary to recommend the following:

To pig farmers: to monitor the health status of animal supply farms and suppliers; avoid visits by strangers, with particular emphasis on former workers from farms infected with red mullet; use tap water and well water on the farm instead of river water; buy pigs only from healthy farms; not to sell the meat of dead animals; isolate and slaughter affected animals;

$>$ To Veterinarians: to use single-use equipment; burn the corpses; implement a curative treatment from the onset of the disease; Strengthen general hygiene precautions; respect collective control measures in the event of swine erysipela.

\section{Compliance with ethical standards}

\section{Disclosure of conflict of interest}

No conflict of interest.

\section{References}

[1] ANONYMOUS Erysipelotrixrhusiopathiae. Porc. Int. Pig. Vet. Soc. Congress, p345, 1992.

[2] BENEDICTED, Maladie professionnelle.Cited 07 march2005 available on http://ww.wmedscape.com/content

[3] BENET JJ. Maladies infectieuses et tropicales, 9'thed., E. PILLY, 2004 
[4] BERNARD G. Médecine tropical. Médecine sciences, 1980.

[5] BRICAIRE F.Infection à " Erysipelothrixrhusiopathiae". Encyclopédie médico-chirurgicale. Maladies infectieuses 8-017-S10. Paris: Editions scientifiquesetmédicales, 2001.

[6] CHAILlON A, Pathologie d'inoculation.Rev. Prat. 2008; 58. 2 : 213-21.

[7] EUZEBY JP. Erysipelothrixrhysiopathiae. Dictionnaire de Bacteriologie Clinique, France 2004.

[8] JEAN B. Corpus Médicale. cited 15 march 2005. Available from http//www.Cnrs.fr/SDV/Rouget

[9] LE BLANC M. et MALAISE F. Lubumbashi, un écosystème urbain tropical. Centre Internationale de Sémiologie, UNAZA, Lubumbashi, 1978.

[10] MULUMBA M.K. L., Contribution à l'Etude du rouget et de la peste porcine en RDC, UNIKIN, Kinshasa 2015.

[11] NICOLAS J. A. Importance d'érysipelothrixrhusiopathiae dans l'étiologie des arthrites infectieuses du mouton. Bull. Acad. Vet.Fr. $1882 ; 52: 33-36$.

[12] PASTEUR L. Sur le rouget ou mal rouge des porcs. C. R. Acad. Sci.1882; 95: 1120-1121.

[13] TOMA. Les principales maladies infectieuses par les écoles Nationales Vétérinaires. Paris, P.172, 2004. 